\title{
Conclusion: Civil Defence Futures (Re)imagined
}

\section{Marie Cronqvist, Rosanna Farbøl, and Casper Sylvest}

As a collective effort, Cold War Civil Defence in Western Europe has sought to bring together new and established perspectives in civil defence history within a theoretical framework sensitive to transnational dynamics: from mighty international organisations to local groups in peripheral areas, from top-down plans and ambitions of authorities to everyday practices of individuals on the ground, from futuristic visions to fuzzy memories and hard materialities, from embracement to resistance. As a whole, the book highlights important and extensive European variations in how societies and peoples grappled with the nuclear threat and how

M. Cronquist

Department of Communication and Media, Lund University, Lund, Sweden e-mail: marie.cronqvist@kom.lu.se

R. Farbøl · C. Sylvest $(\bowtie)$

Department of History, University of Southern Denmark, Odense, Denmark e-mail: csy@sdu.dk

R. Farbøl

e-mail: rosfa@sdu.dk

(C) The Author(s) 2022

M. Cronqvist et al. (eds.), Cold War Civil Defence in Western Europe, https://doi.org/10.1007/978-3-030-84281-9_10 
they were transformed in the process, but it also points to similarities, as well as a myriad of transnational connections. Together, the chapters enrich our understanding of civil defence in the nuclear age within and across national boundaries. In this short conclusion, we offer a few reflections on three themes. First, we bring up the value and challenges of the theoretical approach employed in this book. Second, we highlight the most striking findings, commonalities and differences across the chapters. As a third and final point, we stress the importance of civil defence history at a time when policymakers are once again seeking to promote preparedness and devoting energy and resources to its embedding in cultures, institutions and citizenries.

\section{TheORETICAL Reflections}

One starting point for this book was to explore the merits and potential of studying civil defence through the concept of sociotechnical imaginaries (Jasanoff and Kim 2015; Jasanoff 2015a, b). This approach, presented and discussed in the Introduction to the volume, has provided a common vocabulary, which was central to the ambition of moving beyond a decidedly national tilt in civil defence history and making linkages visible and comparisons possible. Indeed, the framework has sharpened our analytical focus and facilitated comparisons, while allowing for diversity, dynamism and creativity. Moreover, it has allowed us to highlight the central role of technology in civil defence and to study the multiple forms of power that were involved in civil defence practices, whether they involved the rehearsal of strategies for survival during catastrophes, the disciplining of citizens or the (re)shaping of societies and everyday life. While technology and technological development has been a subtext of several existing studies of civil defence history, the benefits of working with a common vocabulary that explicitly theorises the role of technology in social life has allowed us to identify ways in which both nuclear and nonnuclear technologies were integral to civil defence as vision and practice. Finally, the concept of sociotechnical imaginaries has cast light on the social embeddedness of civil defence by focusing attention on how this concept prompted new forms of social interaction and reflected existing social norms in an age when nuclear technologies were swathed in fear of doom and hope of survival. The depth and breadth of the chapters testify to these advantages. 
To be sure, the versatility of the concept of sociotechnical imaginaries - its capacity to be harnessed for a wide variety of research questions and themes in the human sciences-goes a long way towards explaining its uptake and the increasing popularity of the line of questioning the wider approach entails. Yet, this is not the entire story. Another attraction of this approach lies in its tendency to incorporate and connect to a wide range of themes and lines of enquiry that are central to contemporary research in the humanities and social sciences. They include, self-evidently, a resurgence of interest pertaining to the role of science and technology in human life but also a curiosity about the human faculty of imagination, the role of futures in social and political life, a sensitivity to the multifaceted forms of power that are enacted in these contexts and a renewed appreciation of the role of materiality in human interaction.

That said, it is a striking feature of the growing literature that it focuses on brighter visions of technological possibilities - or, to be precise, visions that, although they can be (and are) criticised, centre plainly on the benefits rather than threats to human beings and the world they inhabit. Examples of these imaginaries range from autonomous driving and energy transition to digital transformation, genetically engineered crops and the fourth industrial revolution. ${ }^{l}$ Many of these studies highlight the generative potential of technological future thinking whereby actors not only formulate visions but also (seek to) 'perform and produce' them (Urry 2016: 9). Such studies also harness the critical potential of the concept of sociotechnical imaginaries by highlighting the inconsistencies, gaps or flight of fancy that they tend to entail, thus making clear that sociotechnical imaginaries are 'contested, changeable, flexible and loose around the edges' (Sismondi 2020: 505).

Still, it is remarkable that few studies have so far employed the concept for those imaginaries that are negative, protective or preserving in nature-imaginaries that are overwhelmingly found in areas of health, safety, security and risk. Civil defence is one such case, focused as it is on a safeguarding vision of ensuring resilience, the continuation of social life or bare survival in the face of total war. Overall, we think the chapters in this book demonstrate that the concept of sociotechnical imaginaries is useful for the study of an inherently ambiguous imaginary like civil defence, caught as it was between dystopian and utopian projections.

Fulfilling the ambitions of this collective project and operationalising the theoretical approach in diverse historical contexts and at various levels of analysis has, at times, been complicated. We set out with an open 
mind to explore the potential of the concept of sociotechnical imaginaries in empirical, historical research, and at an early stage we identified a series of challenges, some of which are dealt with briefly in the Introduction to this volume. In addition, several chapters raise and engage with potential shortcomings of the approach such as the tendency to foreground top-down perspectives and the inclination to approach imaginaries within a linear, perhaps even teleological, perspective at the expense of the complexity that historians traditionally emphasise. What emerges from the attempt to use the approach in historical studies of civil defence is the importance of perspective and context for assessing the ways in which imaginaries functioned. This comes to the fore in the chapters that focus on the public sphere or on how civil defence was practised on the ground.

In exploring the concept of sociotechnical imaginaries empirically, the chapters demonstrate that it can indeed be adjusted to inform a range of analyses, just as it is compatible with a series of perspectives and priorities that emerge from the humanistic interest in human beings as both the producers and products of history. Indeed, the contributors to this volume have developed important theoretical adjustments and refinements, while also adding historical depth to the concept of sociotechnical imaginaries. Jasanoff's definition can be read as an instinctively positive evaluation of the role of science and technology in that complex historical development we conveniently (but loosely) refer to as modernity. One example of this is the emphasis on 'desirable futures' in the definition of these imaginaries and their propensity to be 'supportive of' advances in science and technology. On closer inspection, however, and as Bjørnsson discusses in Chapter 2, the concept allows for a wider application and can accommodate a greater degree of complexity than the definition may at first glance suggest. In the context of civil defence, the desirable future is seldom a bright future. The desirable is to find a way to collectively handle the demanding threats to society.

Applying the concept to civil defence places special emphasis on the series of ambivalences about science, technology and progress that often accompanies visions of human futures and modernisation. In some cases, these traits are not only found in forms of resistance but also exist at the very heart of imaginaries. In that context, it is also worth stressing how the notion of civil defence as (forming part of) a sociotechnical imaginary constitutes a balancing act by appealing at once to an amalgam 
of the ideals of a security paradigm (technologised efficiency, organisation, preparation) and a complex of existing norms and values (ranging from social beliefs to humanitarian values). Crucially, these commitments are juggled against a backdrop of uncertainty and controversy created by unfathomable weapons technologies. Theoretically, this points to the importance of legitimacy and credibility in the study of imaginaries revolving around controversial technologies that carry high risks. These themes deserve more theoretical attention within the study of sociotechnical imaginaries.

The intricacies of human-technology relations are revealed especially in the context of the Cold War and in the shadow of nuclear annihilation. Using a wide array of historical sources and analytical approaches, the book advances a multifaceted understanding and application of the concept of sociotechnical imaginaries that highlights social and historical processes in all their ambiguity and 'fuzziness', as Cronqvist and Grant (Chapter 9) term it. Sociotechnical imaginaries of civil defence were real and affected European societies and the lives of people. They were much more than plans, communication, initiatives and constructions rolled out from the top of those societies or their central institutions. While a range of chapters in the book highlight and study these 'official' imaginaries and the myriad attempts at embedding them in norms, institutions and ways of thinking, it is a distinct contribution of this volume to the theoretical discussion of this approach that it underscores how sociotechnical imaginaries are also produced, transformed and inhabited by individuals, organisations and practices in local, regional or professional contexts. We see such processes at work in the social life of North-Western England of the 1950s (Chapter 4), in the development of German disaster medicine (Chapter 3), in the ruin towns of provincial Denmark (Chapter 7) and in opposition to civil defence in the Netherlands and Switzerland (Chapters 6 and 8). This everyday and bottom-up perspective is vital for understanding how sociotechnical imaginaries function.

\section{Common Themes and New Insights}

The book has explored the nature and infrastructures of civil defence imaginaries at the international, transnational, national, regional and local levels. Across these boundaries, a common feature in several of the studies collected in this volume is the Western European delay or difficulty in adapting to the nuclear age. Well into the 1950s, the atomic 
bomb seemed more like an abstraction compared to the more immediate experience of suffering in the recent war. Hence, early imaginaries of civil defence looked to the European past to see the future. The only wartime nuclear attacks the world had experienced, those on Hiroshima and Nagasaki in August 1945, played a surprisingly marginal role. On the European continent, in contrast to a good deal of American civil defence thinking, which saw the beginnings of a transition towards atomic war already in the late 1940s and early 1950s, it was the recent destruction of German cities like Hamburg, Dresden and Cologne and the air raids on allied cities like London that constituted the framework for understanding total war and nuclear defence.

The importance of the Second World War in the early development of European civil defence is highlighted in most of the chapters in this book. Referring to what he calls 'the underlying imagined disastrous', Jochen Molitor states in his contribution (Chapter 3) that this 'was not so much based on the theoretical premises of nuclear warfare, but rather on first-hand experiences of the allied bombings of the recent past'. Furthermore, as demonstrated by Cronqvist and Grant (Chapter 9), for some civil defenders, memories of the Second World War trumped understandings of the Cold War-even when they were explicitly asked to talk about the latter. References to Hiroshima were not absent, but they often served the function of highlighting the astonishing and increasing yield of atomic bombs and confirming a depressing trajectory of modern warfare. The atomic bomb was overwhelmingly shoehorned into an existing world view, despite the recognition, hesitantly at times, that the new weapons technology presented a new, but difficult-to-grasp, invisible danger: radioactivity.

It was only with the arrival of the $\mathrm{H}$ bomb during the mid-1950s that a more systematic rethinking-especially in the public sphere-of the nature of nuclear war and, consequently, sociotechnical imaginaries of civil defence that were markedly nuclear in orientation really emerged (see in particular Chapters 2 and 5). The centre of gravity now lay in an unknown and unstable future. In the House of Commons in March 1955, Winston Churchill famously argued that the British people had entered a period in which safety would be 'the sturdy child of terror and survival the twin brother of annihilation' (Bourke 2006: 261). What this precisely meant for civil defence was not clear at the time, but its effects in Western Europe came to display both similarities and differences. 
One common feature of civil defence thinking in the wake of the $\mathrm{H}$ bomb was that atomic or nuclear war was, on the one hand, accorded more explicit attention in civil defence thinking, communication and practice, while, on the other hand, often appearing as an un(der)specified phenomenon. This was the case, for example, in Britain, Germany, Denmark and Sweden, as illustrated by Molitor (Chapter 3), Hogg (Chapter 4), Farbøl (Chapter 7), and Bennesved and Sylvest (Chapter 5). Strikingly, these countries are marked by obvious and important differences: a nuclear-armed NATO member state (the UK), a NATO member state hosting foreign nuclear weapons (West Germany) and two nonnuclear states (Denmark and Sweden), one a NATO member and the other following a policy of armed neutrality (while secretly pursuing a nuclear weapons capability). Despite these differences, it was a marked feature of the sociotechnical imaginaries of civil defence that were created in these countries, above all by authorities, that there were few, if any, references to the causes or specific nature of the kind of catastrophe that could occur.

At the same time, however, mediations in many of the countries often legitimised ideals of preparedness by referring to (or even exploiting) an abstract sense of Angst and unease. Concrete civil defence practices and exercises also tended to operate with less catastrophic scenarios than full-scale nuclear war. In her chapter on Danish civil defence ruin towns, Farbøl points out that a key line of reasoning was that there was no point in preparing for the impossible. Instead, resources were geared towards manageable scenarios. These include conventional war and limited nuclear attacks (see Chapters 4, 5 and 7), but also peacetime nuclear accidents (Chapters 3 and 8), natural disasters and traffic accidents (see, for instance, Chapters 3 and 6), which paved the way for the kinds of all-hazards approach to emergency management prevalent today. Whether this logic is inherent to imaginaries-that their proponents create meaning by representing their shared visions as seamless and coherent-is an open question.

This recurring calibration of sociotechnical imaginaries of civil defence that sought to strike a balance between capabilities and ambitions and attune new visions of preparedness to existing social norms, expectations and practices is a striking, cross-cutting theme that emerges from this volume. The complex of norms and practices that such imaginaries had to accommodate included not only mundane habits of everyday life but also (gradually shifting) gender roles, notions of good citizenship, and 
national narratives and identities related to security policy or the welfare state.

In repeatedly performing this calibration, also in public, the risk of overstretch was always present, however. Once cracks appeared in the armour of civil defence, and they inevitably did, a host of other questions about its moral justification or allegations of its being out of touch with reality gave rise to (self-)criticism and resistance. In the wider public sphere, and especially among sceptics, detailed speculations about the political dynamics behind a nuclear war and extrapolations of the consequences of war for human life based on scientific opinion served to destabilise official imaginaries. When civil defence demonstrated its efficiency, it was liable to criticism that it was not concerned with the most important threats, and once the limitations to its value in nuclear war were recognised, it was vulnerable to charges of uselessness. Resistance to a sociotechnical imaginary could take the form of friction or outright opposition. In Chapter 6, van Lente details how a maternalist, grassroots imaginary of the women's civil defence organisation developed partly in opposition to the official, paternalist imaginary. At the other end of the spectrum, Molitor (Chapter 3) and in particular Marti (Chapter 8) demonstrate how civil defence was sometimes met with scepticism and even outright resistance, because it was seen as futile or worse: as contributing to the arms race and the likelihood of nuclear war.

The idea that civil defence itself constituted a militarisation of society was a refrain of peace movements in Western Europe-especially during the 1980s - and scholarly research, particularly in the USA, has detailed how everyday life was affected by the logic of militarisation throughout the Cold War (McEnaney 2000). Many mundane aspects of life-from family relations to workplaces and infrastructures of living and mobilitywere transformed and assigned new, additional functions in light of the ever-present risk of nuclear war. Dual-use shelters, for example, crept into the foundations of private and public life. Yet, a larger question that emerges from this book is whether the militarisation thesis puts the cart in front of the horse. Several analyses in this book point in the opposite direction, namely that the increasing public circulation of ideas about survival and preparedness amounted instead to an 'everydayification' of the military.

In the era of total war, the home front mattered more than ever, but the war also took on a new quality as an ever-present, everyday risk and 
never more so than during a cold war. War no longer belonged exclusively to the domain of armies and soldiers, bureaucratic planners and civilians alike played a crucial role in the imaginary war. Though motivated and legitimised by the unique, extraordinary and exceptional (and imagined) disaster, civil defence was, in fact, a part of (real) everyday existence for many citizens and a practical, daily and ordinary activity for volunteers and professional civil defenders. It was (gendered) civic engagement as well as a professional business, as Hogg (Chapter 4), van Lente (Chapter 6) and Cronqvist and Grant (Chapter 9) make clear. Furthermore, as the Cold War progressed, we see the contours of a new sociotechnical imaginary emerge where nuclear war is replaced by an allhazards perspective. In this imaginary, a bracketing of the most apparent low-risk/high-impact catastrophe gives way to a more limited conception of emergency preparedness focused on versatility and application across a wide range of scenarios, as the chapters by Molitor (Chapter 3) and Bennesved and Sylvest (Chapter 5) discuss. Though we still live in the nuclear age, this remains the central focus of European preparedness organisations.

\section{Preparedness Redux}

Among the questions that lie at the core of this book, one is of special contemporary relevance. What knowledge can we attain from civil defence history to the benefit of our contemporary European crisis-ridden societies as they prepare for future disruptions in the areas of health, military conflict, climate change and digital infrastructure? The association of all things atomic with the Cold War era may delude us to think nuclear war is a bygone threat, but that is not the case. There is little doubt that it should be counted among our present-day risks. Notwithstanding renewed campaigns for nuclear disarmament and the adoption of and entry into force of the Treaty on the Prohibition of Nuclear Weapons, the prospects of averting nuclear war through this route currently look dim. Indeed, some nuclear-weapon states are expanding their arsenals, while others have embarked on huge modernisation efforts that amount to a 'qualitative' nuclear arms race. Against this background, it is hardly surprising that in January of 2021 the Science and Security Board Bulletin of the Atomic Scientists kept the symbolic Doomsday Clock at 100 seconds to midnight-closer than it has ever been. The board noted in 
its statement that 'an extremely dangerous global failure to address existential threats $[\ldots]$ tightened its grip in the nuclear realm in the past year, increasing the likelihood of catastrophe'. ${ }^{2}$

Still, the main reference point in the resurgence of preparedness as both planning objective and cultural capital is not nuclear apocalypse but a plethora of risks revolving around human interactions with technology and nature. Disruptions likely to follow in the wake of accelerated climate change, cyber warfare or increasingly perilous pandemics have prompted contemporary scholarship and policymaking to focus on the concept of resilience. In many respects, these threats differ from that of nuclear war, and as the chapters in this volume amply demonstrate, there was much more to civil defence and preparedness during the Cold War than nuclear war (even if it loomed in the background most of the time). Today, resilience is typically understood as an ability to recover a lost equilibrium (or attain a new one) following a large-scale disruption, shock or catastrophe. As Sulfikar Amir has argued, current debates about resilience are marked by a division between two approaches, one stressing the social, cultural and political dimensions and preconditions of this ability, and the second stressing the need for improving and fortifying its technical and material preconditions. Yet, Amir argues, 'resilience is essentially sociotechnical', which means that is best viewed as 'an embedded feature that comes out of a hybrid construct where individuals and communities are blended with the materiality of technology' (Amir 2018: 4). Arguably, this hybrid understanding informs several research and policy initiatives in Europe. The new EU research and innovation framework Horizon Europe, a €95.5 billion programme running from 2021 to 2027 , is one clear example of this trend.

What appears to be still out of sight, though, is that twentieth-century civil defence provides the most complete historical case of such largescale attempts to make preparedness second nature and to make societies resilient. As the chapters in this book demonstrate, civil defence was also thoroughly sociotechnical. Given their inoculation to a mode of thinking that emphasises the central role of context and circumstance in understanding human life, few historians believe that it is possible to transplant historical lessons from one period to another. Neither do we. Our point here is not that Cold War civil defence provides a template for contemporary systems of preparedness. The insights that history provides are of a different order, but no less important. A core observation emerging from this book is that preparedness measures are not independent of their 
political, social and cultural context. They affect, limit or promote particular forms of governance, democratic and civil engagement, social norms, identities and visions of how we ought to co-exist as a society. Historical inquiry is as much a process of imagining or discovering the less familiar and expanding our geographical, cultural and temporal reach as it is anchored in the social and political present. If we let historical knowledge of our sociotechnical past inform present-day concerns, including discussions and debates on threats, fears, resilience and safety, we will be in a better position to make sustainable, complex and mature decisions for our desirable futures. We hope this book has contributed to just such an expansion of horizons.

\section{Notes}

1. Among the plethora of recent studies that deploy the concept of sociotechnical imaginaries, see, for example, Braun and Randell (2020), Graf and Sonnenberger (2020), Gugganig (2021), Hassan (2020), Scholin (2020), and Sovacool et al. (2020).

2. Science and Security Board, Bulletin of the Atomic Scientists, ed. John Mecklin, 'This is your COVID wake-up call: It is 100 seconds to midnight - 2021 Doomsday Clock Statement', available at https://thebulletin.org/wp-content/uploads/2021/01/2021doomsday-clock-statement-1.pdf [accessed 29 March 2021].

\section{REFERENCES}

Amir, Sulfakir. 2018. Introduction: Resilience as sociotechnical construct. In The sociotechnical constitution of resilience: A new perspective on governing risk and disaster, ed. Sulfakir Amir, 1-16. London: Palgrave Macmillan,

Bourke, Joanna. 2006. Fear: A cultural history. London: Virago.

Braun, Robert, and Richard Randell. 2020. Futuramas of the present: the 'driver problem' in the autonomous vehicle sociotechnical imaginary, Humanities of Social Sciences Communications 7 (163): 1-10. https://doi.org/10.1057/s41 599-020-00655-z.

Graf, Antonia, and Marco Sonnenberger. 2020. Responsibility, rationality and acceptance: How future users of autonomous driving are constructed in stakeholder's sociotechnical imaginaries, Public Understanding of Science 29 (1): $61-75$. 
Gugganig, Mascha. 2021. Hawai'i as a laboratory paradise: Divergent sociotechnical island imaginaries. Science as culture. https://doi.org/10.1080/095 05431.2021 .1884217$.

Hassan, Yousif. 2020. The politics of sharing: Sociotechnical imaginaries of digital platforms. Information Polity 25: 159-176.

Jasanoff, Sheila. 2015a. Future imperfect: Science, technology and the imaginations of modernity. In Dreamscapes of modernity: Sociotechnical imaginaries and the fabrication of power, eds. Sheila Jasanoff and Sang-Huyn Kim, 1-33. Chicago: Chicago University Press.

Jasanoff, Sheila. 2015b. Imagined and invented worlds. In Dreamscapes of modernity: Sociotechnical imaginaries and the fabrication of power, eds. Sheila Jasanoff and Sang-Huyn Kim, 321-341. Chicago: Chicago University Press.

Jasanoff, Sheila, and Sang-Huyn Kim, eds. 2015. Dreamscapes of modernity: Sociotechnical imaginaries and the fabrication of power. Chicago: Chicago University Press.

McEnaney, Laura. 2000. Civil defense begins at home: Militarization meets everyday life in the fifties. Princeton: Princeton University Press.

Schiølin, Kasper. 2020. Revolutionary dreams: Future essentialism and the sociotechnical imaginary of the fourth industrial revolution in Denmark. Social Studies of Science 50 (4): 542-566.

Sismondi, Sergio. 2020. Sociotechnical imaginaries: An accidental themed issue. Social Studies of Science 50 (4): 505-507.

Sovacool, Benjamin K., et al. 2020. Imagining sustainable energy and mobility transitions: Valence, temporality, and radicalism in 38 visions of a low-carbon future. Social Studies of Science 50 (4): 642-679.

Urry, John. 2016. What is the future? Cambridge: Polity Press. 
Open Access This chapter is licensed under the terms of the Creative Commons Attribution 4.0 International License (http://creativecommons.org/licenses/ by $/ 4.0 /$ ), which permits use, sharing, adaptation, distribution and reproduction in any medium or format, as long as you give appropriate credit to the original author(s) and the source, provide a link to the Creative Commons license and indicate if changes were made.

The images or other third party material in this chapter are included in the chapter's Creative Commons license, unless indicated otherwise in a credit line to the material. If material is not included in the chapter's Creative Commons license and your intended use is not permitted by statutory regulation or exceeds the permitted use, you will need to obtain permission directly from the copyright holder.

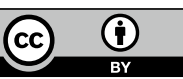

